Royal Meteorological Society: Symons Memorial Medal Award

The Symons Memorial Gold Medal for 1953 of the Royal Meteorological Society has been awarded to Prof. Carl-Gustav Rossby, director of the Meteorological Institute, University of Stockholm, and lately professor of meteorology in the University of Chicago, in recognition of his outstanding contributions to meteorology. The citation states : "He has placed his permanent impress on the fundamental branches of the science from the small-scale turbulence of the lower atmosphere to the dynamics of the largescale currents and their relation to the general circulation of the atmosphere. We esteem Professor Rossby most of all perhaps for the vigorous lead he has given to scientific meteorological research and for his inspiration and encouragement of meteorologists in all parts of the world".

\section{Diffusion of Knowledge}

SPEAkING in Washington on February 13 at a dinner given in his honour, Dr. L. Carmichael, the incoming secretary of the Smithsonian Institution, referred to the tribute which had been paid by Americans on January 16, 1879, to the memory of the first secretary of the Institution, Joseph Henry, who had died eight months previously. That tribute to a great scientist was also a unique official tribute to science itself; but nevertheless Dr. Carmichael wondered whether any real progress has been made in the past seventy-five years in diffusing an understanding of science. In a farewell address to the American Philosophical Society in 1796, Washington had urged, as an object of primary importance, the promotion of institutions for the general diffusion of knowledge, adding that, in proportion as the structure of a government gave force to public opinion, it is essential that public opinion should be enlightened. James Smithson, in bequeathing his property to the United States of America for the founding of the Smithsonian Institution, defined it as "an establishment for the increase and diffusion of knowledge among men", and Andrew Carnegie, who for many years placed the motto "Let there be light" in all the libraries he established, is said to have believed that enlightenment is the one general remedy for the ills that beset the human race. Although pure and applied science to-day find unequalled public and private support in many sections of the nation, Dr. Carmichael believes it is still necessary to defend research expenditure by referring to the immediate practical utility of the investigations. We still need a society for propagating the understanding of the true place of science in society. The great human advantages which the world would derive through the proper support of science must be told and told again in clear and popular language. Washington, Smithson and Carnegie envisaged a happy marriage between research and public information, and Dr. Carmichael thinks that scientists should see that neither selfishness nor inertia prevents their participation in the task of interpreting science to the millions and assisting the expert science writers in a task to which they have already brought intelligence, enthusiasm and dedicated service.

\section{Journal of Rational Mechanics and Analysis}

Is the first four numbers of a new quarterly, the Journal of Rational Mechanics and Analysis (published by the Graduate Institute for Applied Mathematics, Indiana University, Bloomington, Ind.), there are, in all, some twenty papers running to about six hundred and fifty pages of print, and it is now possible to review the Journal during the first year of its existence. The editors are Profs. T. Y. Thomas and C. Truesdell, and the eminent editorial board, numbering twenty-six, is drawn in about equal proportions from United States universities and institutes of technology and from the corresponding institutions in various countries of western Europe. The purpose of the Journal, as stated on the inside front cover, is "to close the rift between 'pure' and 'applied' mathematics and to foster the discipline of mechanics as a deductive, mathematical science in the classical tradition. Its scope comprises those parts of pure mathematics or other theoretical sciences which contribute to mechanics; among the included fields are all branches of analysis, differential geometry, analytical dynamics, elasticity, fluid dynamics, plasticity, thermodynamics, relativity and statistical mechanics. Engineering applications, numerical work, perturbation procedures, etc., are acceptable only as incidental illustration in a paper devoted to sound mathematical theory". The papers published to date are fully consistent with this point of view, being primarily pure mathematical in character and outlook, and having the explanation of natural phenomena as but a secondary objective. In this respect, the Journal is in marked contrast to the Quarterly Journal of Mechanics and Applied Mathematics (Oxford University Press). That there is a place for the publication of papers of the kind just described is beyond doubt, but the extent of the interest which such papers are likely to arouse is open to question. With regard to subject-matter, there have so far been nine papers on fluid dynamics, three on elasticity or plasticity, one on relativity and one on analytical dynamics, while the remaining six have ranged over a wide variety of topics. The subscription price of the Journal is 6 dollars a volume for individuals engaged in research or teaching, but 18 dollars for everyone else; by British standards, the latter figure is distinctly high.

\section{Recruitment of Scientists and Technologists in Great Britain}

IN reply to a question in the House of Commons on April 28, the Chancellor of the Exchequer, Mr. R. A. Butler, stated that the number of scientists and technologists coming from the universities and technical colleges of Great Britain with degrees, Higher National Certificates and Higher National Diplomas, or their equivalent, during the academic year 1951-52 was estimated to be one in about 2,600 of the population. Mr. Butler added that the Government is doing its best to improve the facilities for technological education; he concurred with the suggestion that there is still great difficulty in persuading engineering and other firms to employ the scientists and technologists in the works, and that industry requires a great deal more encouragement to make use of the highest and best form of knowledge.

\section{A Model Rehabilitation and Training Centre}

IN May 1952 the President of the Austrian Republic performed the opening ceremony of what is probably the finest rehabilitation and training centre to be found in Europe. It is situated at Tobelbad, about nine miles from Graz, and has been built on the site of a former spa (Rehabilitation, 7; January 1953). Extensive new buildings have been erected over the site of the hot springs affording ample accommodation 